\title{
Ureteroscopy with conscious sedation for distal ureteric calculi: 10-year experience
}

\author{
Tadeusz J. Kroczak, MD;' Kamaljot Singh Kaler, MD, FRCSC,; Premal Patel, MD;' Turki Al-Essawi, MD, FRCSC ${ }^{3}$
}

'University of Manitoba, Section of Urology, Winnipeg, MB, Canada; ' University of California Irvine, Department of Urology, Irvine, California, U.S; ${ }^{3 S a a d ~ S p e c i a l i s t ~ H o s p i t a l, ~ A l-K h o b a r, ~ S a u d i ~ A r a b i a ~}$

Cite as: Can Urol Assoc J 2016;10(1-2):E12-6. http://dx.doi.org/10.5489/cuaj.3302 Published online January 14, 2016.

\section{Abstract}

Introduction: Distal ureteroscopy for stone extraction is a common procedure that is generally performed with spinal or general anesthesia. We retrospectively reviewed all distal ureteroscopy performed for ureteric stone extraction with conscious sedation at our institution over a 10-year period to determine its efficacy and safety.

Methods: A retrospective chart review was performed of all distal ureteroscopy performed for calculus removal from 2004 to 2014. Patient characteristics, analgesic requirement, tolerability, procedure time, stone size and composition, method of stone extraction, success rate, and complications were collected.

Results: Between 2004 and 2014, 314 procedures were performed. Mean age was 53.74 years, with 160 males and 154 females. A success rate of $97 \%$ and $10(3.2 \%)$ complications were reported. Mean analgesic requirement was $189 \mu \mathrm{g}$ of fentanyl (range: 50-400) and $2.79 \mathrm{mg}$ of midazolam (range: $0-8)$. A total of 263 patients $(83.7 \%)$ tolerated the procedure well, with only seven $(2.2 \%)$ having poor tolerability. When comparing females to males, females were found to require less fentanyl $(p=0.0001)$ and midazolam $(p=0.0001)$. When calculi $>5 \mathrm{~mm}$ were compared to those $<5 \mathrm{~mm}$, there was no statistically significant difference in success rate, procedure time, analgesic requirement, tolerability, or complications.

Conclusion: Distal ureteroscopy with conscious sedation is safe and efficacious. To our knowledge, this is the first report demonstrating stones $>5 \mathrm{~mm}$ can be safely and effectively treated with conscious sedation during this procedure. The context of our findings must be understood within the limitations of our retrospective analysis.

\section{Introduction}

Distal ureteric stones are often treated with observation and/or medical expulsive therapies, extracorporeal shockwave lithotripsy (ESWL) or distal ureteroscopy under spinal or general anesthesia. ESWL and distal ureteroscopy have both been shown to be safe and effective treatments.
Stone removal via ureteroscopy usually requires an operating theatre and general anesthetic, in contrast to ESWL, which is typically performed under conscious sedation. ${ }^{1,2}$ Ureteroscopy under local anesthesia was first described by Rittenberg et al in $1987 .^{3}$

Since January 1993, distal ureteroscopy under conscious sedation has been offered at our centre for the removal of distal ureteric stones. A proof of principle analysis at our centre demonstrated the feasibility and safety of this procedure. ${ }^{4}$ Subsequent to this analysis in 2003, our centre compared ESWL and distal ureteroscopy for distal ureteric stones and found treatment success in $72 \%$ and $95 \%$ of patients, respectively. ${ }^{5}$ These results also showed men were less likely to tolerate ureteroscopy under conscious sedation compared to women.

In this study, we report an updated analysis of all distal ureteroscopies under conscious sedation performed for distal ureteric stone extraction at our institution over a 10-year period to evaluate its safety and efficacy over the long term.

\section{Methods}

Since 1993 our institution has offered distal ureteroscopy with conscious sedation for ureteric calculi treatment. A retrospective chart review of all distal ureteroscopies performed for calculi removal from April 2004 to April 2014 was executed. Indications for ureteroscopy ranged from failure of conservative management (typically three to four weeks), failure of extracorporeal shock wave lithotripsy, repeat visits to emergency department for renal colic, or patient preference. Some patients had prior stents inserted due to pain or sepsis. Patients with a single stone of varied size were offered distal ureteroscopy with conscious sedation after informed consent. Patient list was generated using ureteroscopy billing code under conscious sedation. Distal ureteroscopy was defined as stones below the pelvic brim.

Our centre has a cystoscopy suite equipped with built-in fluoroscopy. Vitals (blood pressure, heart rate, oxygen satura- 
tion) are continuously monitored throughout the procedure, as well postoperatively. Two nursing staff trained in intravenous sedation were present during the procedure. Fentanyl and midazolam were used for conscious sedation in the majority of patients. In most patients, initial doses of $100 \mu \mathrm{g}$ of fentanyl and $2 \mathrm{mg}$ of midazolam were administered prior to initiation of the procedure. Dosing was adjusted in elderly patients and those with impaired pulmonary or cardiac function. Additional doses of fentanyl and midazolam were given if the patient began to experience discomfort. Fentanyl was usually given in 25-50 $\mu$ g increments and midazolam with additional $1 \mathrm{mg}$ doses. Oxygen was administered via nasal prongs to achieve an oxygen saturation of $>90 \%$. All patients were monitored for at least one hour by nursing staff in a recovery room after the procedure. To ensure proper use of resources, nursing stuff were responsible for monitoring patients after ESWL, as well as colonoscopies performed by gastroenterology.

Ureteroscopy was performed using a 6 French rigid ureteroscope in the majority of patients. Access to the ureter was aided by balloon dilation of the distal ureteric orifice if the stone was large, the orifice appeared narrow or stenotic, or multiple entry into the ureter was anticipated. A four-wire helical stone basket was used to manipulate the stone under direct vision and a Swiss pneumatic lithoclast was used for large calculi. Ureteric stents were inserted at the discretion of the urologist.

Urologist and the nursing staff monitored the patient closely for tolerance of the procedure. Objective and subjective findings were used to classify the procedure as "good," "fair," or "poor." If the patient had minimal or no complaints of discomfort or complaints that easily resolved with minimal additional analgesia (one or two additional doses), the procedure was classified as "good." If the patient required additional doses of analgesic or sedation (three or four additional doses), complained of discomfort, or a noticeable increase in pulse rate or blood pressure was seen, the procedure was classified as "fair." Tolerance was also assessed as fair if no consensus could be reached regarding the patient's tolerance. If the patient required significant amounts of analgesic or sedation (more than four additional doses), complained of pain, and had significant increase in heart rate or blood pressure, the procedure was classified as "poor."

Patient characteristics, analgesic requirement, tolerability, procedure time, stone size and composition, method of stone extraction, success rate, and complications were collected. Success was defined as removal of the intact stone or fragmentation of the stone to allow easy passage into the bladder. Using the parameters listed above, we compared male patients to female patients, as well as calculi $<5 \mathrm{~mm}$ to those $\geq 5 \mathrm{~mm}$. Fishers exact test, chi-squared, and unpaired t-test were used for data analysis.

\section{Results}

Between April 2004 and April 2014, 314 distal ureteroscopies were performed. Patient and clinical characteristics are shown in Table 1. Mean patient age was 53.74 (range 17-88), with 160 (51\%) males and $154(49 \%)$ females in our cohort. Mean stone size was $4.84 \mathrm{~mm}$ (range: 1-18 $\mathrm{mm})$, with an overall success rate of $97 \%$. Mean fentanyl and midazolam required during procedure was $189.01 \mathrm{ug}$ (range: 50-400) and $2.79 \mathrm{mg}$ (range: 0-8), respectively. With regards to procedural tolerability, only seven patients (2\%) had poor tolerability. Of 314 ureteroscopies, only 10 patients (3.2\%) had complications, with only 16 patients $(5.1 \%)$ requiring hospital admission.

As demonstrated in Table 2, when comparing females to males, males were found to be slightly older (55.95 vs. 51.45 year, $p=0.0074$ ), with females found to require less

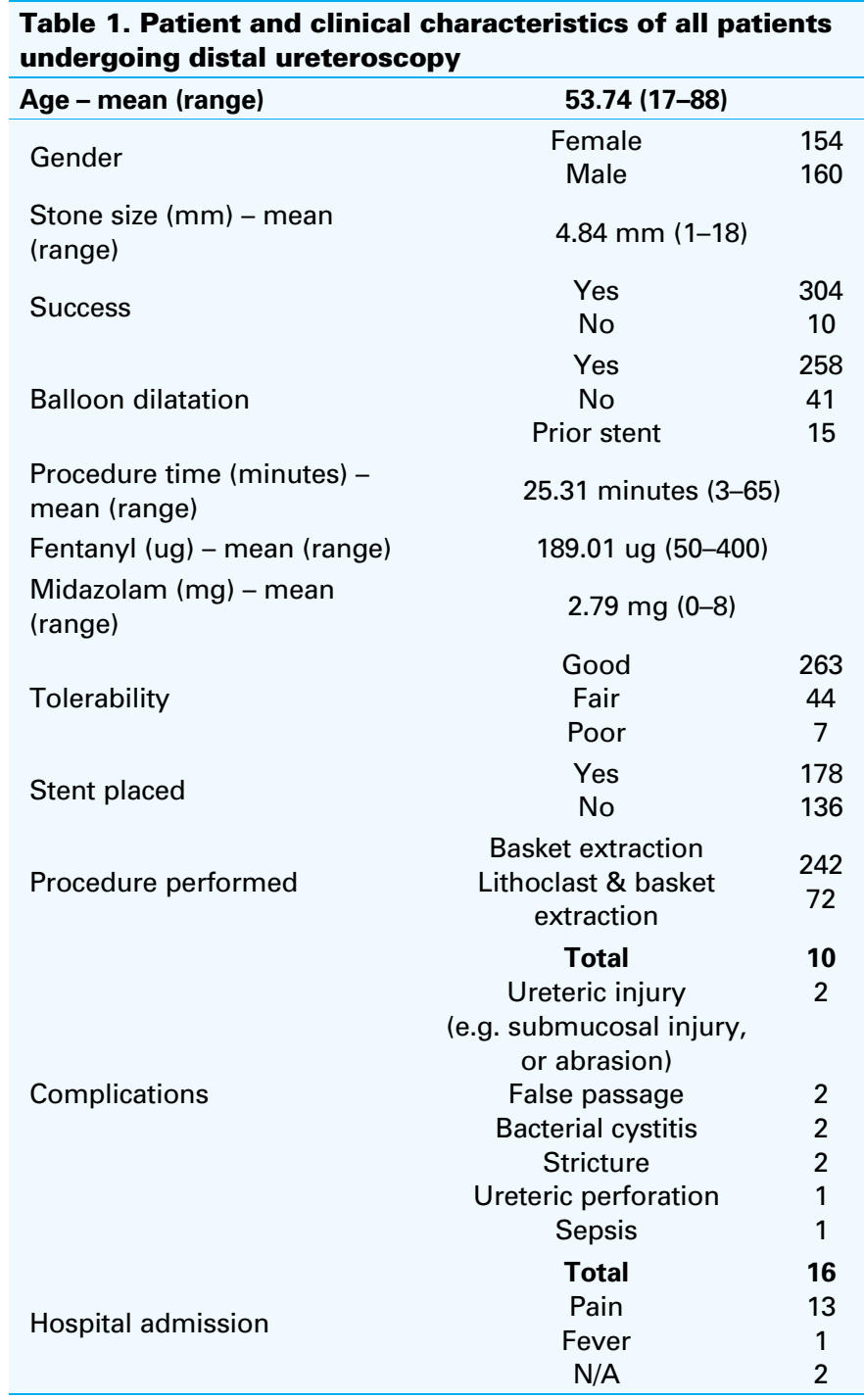


Kroczak et al.

\begin{tabular}{|c|c|c|c|c|}
\hline Gender & & Male & Female & $p$ value \\
\hline & & 160 & 154 & \\
\hline Age - mean (range) & & $55.95(19-85)$ & $51.45(17-88)$ & 0.0074 \\
\hline Stone size $(\mathrm{mm})$ - mean (range) & & $4.62 \mathrm{~mm}(1-18 \mathrm{~mm})$ & $5.06 \mathrm{~mm}(1-12)$ & 0.0660 \\
\hline Success & $\begin{array}{l}\text { Yes } \\
\text { No }\end{array}$ & $\begin{array}{c}153 \\
7\end{array}$ & $\begin{array}{c}151 \\
3\end{array}$ & 0.3367 \\
\hline $\begin{array}{l}\text { Procedure time (minutes) - mean } \\
\text { (range) }\end{array}$ & & $\begin{array}{l}25.79 \text { minutes } \\
(3-65)\end{array}$ & $\begin{array}{l}24.81 \text { minutes } \\
(10-60)\end{array}$ & 0.3983 \\
\hline Fentanyl (ug) - mean (range) & & $\begin{array}{l}204.22 \text { ug } \\
(50-400)\end{array}$ & $\begin{array}{l}173.21 \mathrm{ug} \\
(50-400)\end{array}$ & 0.0001 \\
\hline Midazolam (mg) - mean (range) & & $3.06 \mathrm{mg}(0-8)$ & $2.51 \mathrm{mg}(1-8)$ & 0.0001 \\
\hline Tolerability & $\begin{array}{l}\text { Good } \\
\text { Fair } \\
\text { Poor }\end{array}$ & $\begin{array}{c}127 \\
28 \\
5\end{array}$ & $\begin{array}{c}136 \\
16 \\
2\end{array}$ & 0.0928 \\
\hline Complications & $\begin{array}{l}\text { Yes } \\
\text { No }\end{array}$ & $\begin{array}{c}5 \\
155\end{array}$ & $\begin{array}{c}5 \\
149\end{array}$ & 1.000 \\
\hline Hospital admission & $\begin{array}{l}\text { Yes } \\
\text { No }\end{array}$ & $\begin{array}{c}6 \\
154\end{array}$ & $\begin{array}{c}10 \\
144\end{array}$ & 0.3120 \\
\hline
\end{tabular}

fentanyl $(p=0.0001)$ and midazolam $(p=0.0001)$. There was no difference with regards to stone size, success rate, procedure time, tolerability, complications, or hospital admission.

When calculi $>5 \mathrm{~mm}$ were compared to those $<5 \mathrm{~mm}$, there was no statistically significant difference in gender, age, success, procedure time, analgesic requirement, tolerability, stent placement, complications, or hospital admission ( Table 3).

\section{Discussion}

For over 22 years, we have performed distal ureteroscopy with intravenous sedation. An initial experience from our centre was published in 1993. However, only patients with stones $<5 \mathrm{~mm}$ were included in that analysis. Of the 68 patients who had distal ureteric stones, 66 (97\%) were removed successfully, with $56(83 \%)$ of patients tolerating the procedure well with no intra-operative complications. ${ }^{4}$ Subsequent to that analysis, a study at our centre by Hosking et al compared 110 patients undergoing 138 ESWL treatments vs. 172 patients undergoing ureteroscopy under intravenous sedation for the management of ureteric calculi. ${ }^{5}$ Treatment success was $72 \%$ and $90 \%$ in the ESWL and ureteroscopy groups, respectively.

Our updated analysis of 314 patients with distal ureteric stones demonstrates similar findings, with an overall success of $97 \%$. In the majority of cases ( $n=242,77 \%)$, basket extraction was sufficient for removal of the stone. However, a small subset of patients required balloon dilatation of the ureteric orifice $(n=41,13 \%)$. Only seven patients $(2.2 \%)$ had poor tolerability with a low complication $(3.2 \%)$ and hospital admission rate $(5.1 \%)$. A recently published analysis of a prospective global database demonstrated an overall complication rate of $3.8 \%$ and a less than three-month hospital admission rate of $6.7 \%$ for 4477 patients undergoing semirigid or flexible ureteroscopy for distal ureteric calculi. ${ }^{1}$ Further, our study demonstrated that the majority of patients had stones $>5 \mathrm{~mm}$ and no significant differences were noted in procedure time, tolerance, analgesic/sedation requirements, complications, admissions, and success rates (Table 3).

The updated analysis by Hosking et al found men tolerated ESWL better than ureteroscopy, with over $90 \%$ of women tolerating both procedures well. ${ }^{5}$ In our analysis, we found male patients required more fentanyl (204.22 vs. 173.21; $\mathrm{p}=0.0001)$ and midazolam (3.06 vs. $2.51 ; \mathrm{p}=0.0001)$ compared to females. However, there was no statistically significant difference with regards to overall procedure tolerability $(p=0.928)$. Furthermore, the difference, although statistically significant, is unlikely to be of clinical significance, as the additional required doses were small.

A study by Park et al in 2004 evaluated 200 patients undergoing ureteroscopy under local sedation and found an overall success rate of $93 \%$, with a complication rate of $3 \% .^{6}$ To determine tolerability, they designed a prospective study for comparison of pain during cystoscopy and local ureteroscopic lithotripsy using a visual analogue scale. The mean pain scale score was higher in the ureteroscopy group (3.36 vs. 3.13), although this was not found to be statistically significant. In 2005, a prospective study by Rao et al included 124 patients with a success rate of $91.94 \%$ and an overall complication rate of $2 \% .^{7}$ This study used a visual analogue scale to measure tolerability, with $80.7 \%$ of patients stating they had only $10-20 \%$ of pain. Chan et al also had comparable overall success rate of $78 \%{ }^{8}$

Our study, along with others, has shown the feasibility and safety of performing distal ureteroscopy under conscious sedation. However, patient selection is of utmost importance 


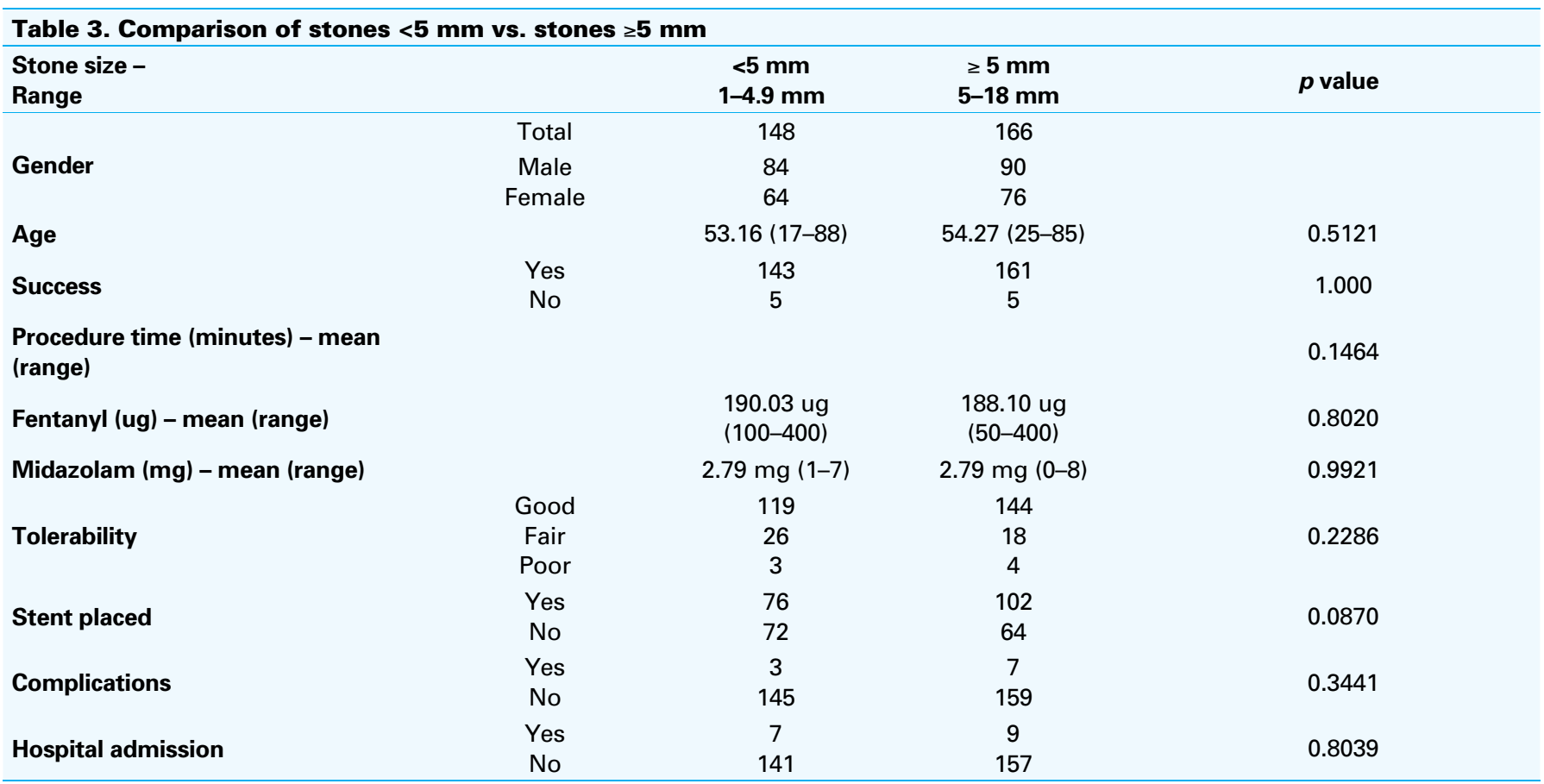

and tolerance should be assessed prior to performing this procedure to optimize success.

\section{Limitations}

Although our results demonstrate the feasibility and safety of distal ureteroscopy under conscious sedation, it is not completely void of limitations. A significant limitation is that patient charts were retrieved using billing codes for distal ureteroscopy. If a patient was unable to tolerate scope insertion and procedure was terminated, this would not be captured on our retrieval list. Furthermore, patients may have presented to a referring hospital or their family doctor with complications and these may not have been captured. Our study was completed retrospectively and our pain measures were ascertained subjectively without using a standardized pain questionnaire. Stone size was determined by X-ray, computed tomography, or biochemical specimen analysis. Two patients were admitted to hospital after their procedure; however, we were unable to determine the reason for admission.

\section{Conclusions}

Our series is the largest to demonstrate the safety and effectiveness of performing distal ureteroscopy under conscious sedation. We found females required less fentanyl and midazolam; however, this is unlikely to be of clinical significance. Further, there was no difference in overall tolerability.
Also, for the first time, we demonstrate that this procedure can be performed equally effectively in stones $>5 \mathrm{~mm}$. With limited operating room time available in our healthcare system, this technique frees operating room time for more pertinent cases requiring general or spinal anesthesia without compromising efficacy or patient safety.

Competing interests: The authors declare no competing financial or personal interests.

This paper has been peer-reviewed.

\section{References}

1. Castro EP, Osther PJ, Jinga V, et al. Differences in ureteroscopic stone treatment and outcomes for distal, mid-, proximal, or multiple ureteral locations: The Clinical Research Office of the Endourological Society Ureteroscopy Global Study. Eur Urol 2014;66:102-9. http://dx.doi.org/10.1016/i.eururo.2014.01.011

2. Honeck $P$, Häcker $A$, Alken $P$, et al. Shock wave lithotropsy versus ureteroscopy for distal ureteral calculi: A prospective study. Urol Res 2006;34:190-2. http://dx.doi.org/10.1007/s00240-006-0041-9

3. Rittenberg MH, Ellis DJ, Bagley DH. Ureteroscopy under local anesthesia. Urology 1987;30:475-8. http:// dx.doi.org/10.1016/0090-4295(87)90385-2

4. Hosking DH, Bard RJ. Ureteroseopy with intravenous sedation for treatment of distal ureteric calculi: A safe and effective alternative to shock wave lithotripsy. J Urol 1996;156:899-902. http://dx.doi. org/10.1016/S0022-5347(01)65654-4

5. Hosking DH, Smith W, McColm S. A comparison of extracorporeal shock wave lithotripsy and ureteroscopy under intravenous sedation for the management of distal ureteric calculi. Can J Urol 2003;10:1780-4.

6. Park HK, Paick SH, OhSJ, et al. Ureteroscopic lithotripsy under local anesthesia: Analysis of the effectiveness and patient tolerability. Eur Urol 2004;45:670-3. http://dx.doi.org/10.1016/j.eururo.2004.01.003

7. Rao MP, Kumar S, Dutta B, et al. Safety and efficacy of ureteroscopic lithotripsy for ureteral calculi under sedoanalgesia: A prospective study. Int Urol Nephrol 2005;37:219-24. http://dx.doi.org/10.1007/ s1 1255-004-7969-x 
Kroczak et al.

8. Chan PSF, Fenn J, Li AKC. Transurethral ureteroscopic lithotripsy and retrieval of ureteric calculi under local anaesthesia and sedation. Br J Urol 1990;65:141-3. http://dx.doi.org/10.1111/i.1464-410X.1990. tb14684.x
Correspondence: Dr. Premal Patel, University of Manitoba, Section of Urology, Winnipeg, MB, Canada; premalpatel8@gmail.com 